\title{
SOBRE LAS CONSECUENCIAS JURÍDICAS DE LA SENTENCIA 31/2010, DE 28 DE JUNIO, DEL TRIBUNAL CONSTITUCIONAL SOBRE EL ESTATUTO DE CATALUÑA
}

GERVASIO MARTÍN MARTÍN 
SUMARIO

1. NORMALIDAD INSTITUCIONAL. 2. SOCIOLOGÍA, CULTURA Y TRIBUNAL CONSTITUCIONAL. 3. LA JURISPRUDENCIA CONSTITUCIONAL. LA LIBERTAD DE LOS TRIBUNALES. 4. ÁMBITOS TEMÁTICOS AFECTADOS. 5. LA INCIDENCIA DE LA SENTENCIA SOBRE OTRAS NORMAS. 6. CONCLUSIONES. 


\title{
SOBRE LAS CONSECUENCIAS JURÍDICAS DE LA SENTENCIA 31/2010, DE 28 DE JUNIO, DEL TRIBUNAL CONSTITUCIONAL SOBRE EL ESTATUTO DE CATALUÑA
}

\author{
GERVASIO MARTÍN MARTÍN \\ Letrado Consejo General del Poder Judicial \\ Magistrado del Tribunal Superior de Madrid
}

\section{NORMALIDAD INSTITUCIONAL}

La normalidad institucional es un valor esencial para el Estado de Derecho. Hasta el punto de que las anormalidades en el funcionamiento institucional se traducen en una pérdida de confianza en el sistema social en general y en el Derecho en particular, lo que origina una suerte de ansiedad social ${ }^{1}$. La Sentencia 31/2010, de 28 de junio, del Tribunal Constitucional sobre el Estatuto de Cataluña es una piedra de toque para estas cuestiones.

Rosario Tur Ausina y Enrique Álvarez Conde, desde su posición privilegiada de la docencia y la investigación, han dado a la luz en Aranzadi-Thomson Reuters a un libro que estudia las consecuencias jurídicas de esta sentencia, que en gran parte se denomina por el propio Tribunal como la de la perfecta libertad.

${ }^{1}$ OSCAR G. CHASE. Derecho, cultura y ritual. Sistemas de resolución de controversias en un contexto intercultural. Marcial Pons, 2011. Pág. 125. 
El objeto del libro es, como dicen los autores, «el análisis, doctrinal y científico de la sentencia del Tribunal Constitucional 31/2010 y sus consecuencias jurídicas». Se centra en el aspecto jurídico, si bien es evidente que existen otros aspectos relevantes que reclaman su análisis. En efecto, las sociedades actuales conforman un entramado complejo de relaciones en el que las decisiones de los Tribunales, y señaladamente del Tribunal Constitucional, constituyen un elemento relevante. Así, se dice que no es exagerado afirmar que el enorme, complejo y productivo sistema económico actual es producto del Derecho ${ }^{2}$. De otra parte el Derecho, y en especial el Derecho Constitucional, se proyecta sobre una parcela de la actividad humana que tiene como materia primaria la actividad política, de manera que en él se cumple la regla que dice ${ }^{3}$ que el Derecho nos protege del poder político en bruto, por cuanto crea instituciones políticas, y cuando se nos somete a ellas se ve como algo correcto, legítimo, precisamente por ser creadas por el Derecho que actúa como instrumentos protector. Averiguar o encontrar los criterios aceptables o aceptados de legitimación darán consistencia a las propias instituciones, para lo que es imprescindible averiguar si el centro de la decisión judicial se ubica en el Derecho, en este caso en la Constitución, de donde se desprenderá su propia fortaleza e irresistibilidad, o en la política pura, de donde se desprenderá su rechazo o, cuando menos, discusión.

Lo primero se produce por una causa aparentemente paradójica: se acepta la decisión del Tribunal por ser el resultado derivado de la mera aplicación de la Constitución, esto es, de una norma que el Tribunal no ha promulgado ${ }^{4}$, por lo que el Tribunal es concebido sociológica y culturalmente como un poder subordinado al verdadero poder soberano e irresistible. Su prestigio y acatamiento se conecta con la convicción de que no aplica su voluntad, sino la de otro (la división de poderes es el presupuesto sociológico y cultural de su aceptación e irresistibilidad). Lo segundo será la consecuencia de que el Tribunal ha actuado como poder primario, político, y por ello fijando la regla de la decisión, utilizando en tal caso la Constitución como pretexto.

2 Opus cit. Pág. 69.

3 Opus cit. Pág. 71.

${ }^{4}$ L.L Fuller. The Forum and Limits of Adjudication, 92 Harvard Law Review; 1978, pp. 353409. Citado por OSCAR G. CHASE. Opus cit. Pág. 126. 


\section{SOCIOLOGÍA, CULTURA Y TRIBUNAL CONSTITUCIONAL}

El libro de Rosario Tur Ausina y Enrique Álvarez Conde, que lleva por título «Las consecuencias jurídicas de la Sentencia 31/2010, de 28 de junio, del Tribunal Constitucional sobre el Estatuto de Cataluña. La Sentencia de la perfecta libertad», nos ofrecerá las claves para abordar este camino, que en mi opinión no se termina en este texto de estudio y análisis de la referida sentencia.

En efecto, esta Sentencia del Tribunal Constitucional ofrece a los estudiosos un campo muy interesante de análisis, que trasciende a ella misma, para proyectarse, especialmente, sobre el propio Tribunal Constitucional, que presenta unas perspectivas novedosas que deben tenerse en cuenta: la situación política del momento, la tensión entre un nacionalismo centrífugo (real) que se opone según él a un nacionalismo centrípeto (que es negado frente a los que militan en el anterior nacionalismo, que son los que más sostienen la existencia de este nacionalismo), las tensiones internas del propio Tribunal (con novedosas recusaciones de compleja articulación en un órgano como el Tribunal Constitucional—, con una composición numérica reducida y con mandato agotado en algunos casos), y muy en especial, la técnica jurídica seguida, ciertamente oscilante entre el principialismo y el pragmatismo. A ello se une la propia naturaleza del Estatuto, el complejo proceso de aprobación, la duración del proceso de constitucionalidad, el desarrollo que desde su aprobación ha tenido e, incluso, la referencia que para otras reformas estatutarias representaba5.

Algo de todo ello preocupa al propio Tribunal Constitucional cuando considera a su sentencia como la «de la perfecta libertad (del Tribunal)», y a los propios autores del referido libro cuando sostienen que se debe superar (la sentencia) cuanto antes, ya que no ha sabido o podido (el Tribunal) dar respuesta a los planteamientos existentes, y produce una desactivación de la reforma estatutaria catalana y que por ello no va a ser una sentencia de referencia, pues no cumple la finalidad de la sentencias constitucionales al no conseguir la seguridad jurídica, ya que después de ella, y por abusar de la «in-

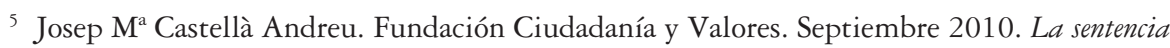
del tribunal constitucional 31/2010, sobre el estatuto de autonomía de Cataluña y su significado para el futuro del estado autonómico. La lógica intrínseca del sistema constitucional español con respecto a la reforma de los Estatutos de Autonomía consiste en exigir amplios consensos internos en la comunidad autónoma para su aprobación (en el Parlamento autonómico y, en los casos de las CCAA con procedimiento especial de reforma, entre la ciudadanía) y en las Cortes (aprobación con el procedimiento de Ley Orgánica, por mayoría absoluta del Congreso).

(C) UNED. Revista de Derecho Político 
terpretación conforme ${ }^{6} »$ nos encontramos con varios Estatutos: el que resulta de las declaraciones de inconstitucionalidad, el de las interpretaciones conforme llevadas al fallo, y el de estas mismas interpretaciones no llevadas al fa1lo. En suma, la STC 31/2010 ha aumentado la inseguridad jurídica, pues en gran parte reconstruye todo el mandato normativo, alterando la literalidad de los preceptos, haciéndoles decir lo que no dicen y contradiciendo la voluntad del legislador democrático.

Dice ATIYAH ${ }^{7}$, que en la primera mitad del siglo XIX, los Tribunales se posicionaban para resolver los conflictos (entre los principios y el pragmatismo) del lado de los principios, pues estaban más preocupados por el impacto de sus resoluciones hacia el futuro, que por hacer justicia en cada caso particular. En los tiempos modernos, por el contrario, entiende que los Tribunales se han vuelto más pragmáticos y menos principialistas. Pues bien, la Sentencia 31/2010, de 28 de junio, del Tribunal Constitucional, no se ubica, como antes se destacó, con claridad en una de esas dos posiciones, moviéndose también en la misma indefinición de la Constitución en cuanto al modelo de Estado, y siendo reflejo también de la ausencia de un gran Pacto de Estado en materia de reforma de los Estatutos de Autonomía, a diferencia del que estuvo presente en otras épocas ${ }^{8}$.

El carácter abierto del modelo territorial de Estado ${ }^{9}$, así como la ausencia de ese Gran Pacto de reforma que permitiera acometer en el siglo XXI un proceso

${ }^{6}$ G. de Vergottini. «Más allá del diálogo entre Tribunales. Comparación y relación entre jurisdicciones» (prólogo de Javier García Roca y traducción de Pedro J. Tenorio Sánchez). Cuadernos Civitas de Thomson Reuters, Editorial Aranzadi. Civitas 2010, destaca la importancia de esta técnica como garantía del vínculo de adecuación sucesiva entre distintos Tribunales a los pronunciamientos de ellos mismos pudiendo considerarse como técnica de colaboración entre los Tribunales internos y los supranacionales. En este caso, esa adecuación se daría con la propia Constitución, o por mejor decir con el propio legislador, cuya voluntad expresada en la Ley (Estatuto) debe ser conservada.

7 ATIYAH, P.S. From principles to pragmatismo: Changes in the function of the judicial process and the law. Iowa Law Review. num. 65, 1980, pp. 1249-1271. Citado por OSCAR G. CHASE Opus cit., en Pág. 124.

8 E. ALVAREZ CONDE, Reforma constitucional y reformas estatutarias, Madrid 2007. Suele señalarse que al ser el texto constitucional un texto totalmente abierto, en el cual apenas hay constitucionalizados una serie de principios, unos concretos procedimientos, y unos determinados órganos constitucionales, caracterizándose, en suma, por ser una norma meramente procesal, es necesario proceder a la complementación de aquella por una serie de normas, especialmente los Estatutos de Autonomía, que pasarían a integrar la denominada «Constitución material», lo que podría llevar a intentar un cambio del modelo de Estado desde los propios Estatutos de Autonomía, en una especie de «mutación del poder de reforma».

9 Cfr., a este respecto, I. DE OTTO, «La Constitución abierta», Revista de Occidente, núm. 54, noviembre de 1985 . 
profundo de reformas estatutarias, precedido seguramente de la pertinente reforma constitucional, ha dado origen a que se deposite en el Tribunal Constitucional la responsabilidad de perfilar la configuración territorial futura del Estado, de ahí que se hable del «Estado jurisprudencial autonómico». Este papel del Tribunal Constitucional no puede ser realizado con naturalidad en tanto que no es el órgano encargado de escribir el curso de la actividad política, y el hecho de que pueda actuar conforme a criterios pragmáticos, estos se mueven en el contexto del litigio y constreñidos por los márgenes del proceso constitucional, mucho más agostos que el cauce político; por lo, lo exigible al Tribunal Constitucional es la fijación o aclaración de los principios, pero no su traducción en decisiones concretas y abiertas para el futuro. La perfecta libertad es, por ello, la del legislador estatuario, que siempre se puede aventurar hasta los límites que resulten de la Constitución, en cuya averiguación si serán relevantes los principios fijados por el Tribunal Constitucional.

Como se puede advertir, esta situación significa trasladar al Tribunal Constitucional una función que ataca al núcleo de su prestigio y aceptación. En efecto, ya no va aplicar la norma creada por un tercero (el constituyente), sino que va a ser quien, en gran medida, «crea» la norma ${ }^{10}$, con lo que se percibe como poder político, pasando sus decisiones a ser, no de la Ley (de la Constitución), sino de los hombres.

\section{LA JURISPRUDENCIA CONSTITUCIONAL. LA LIBERTAD DE LOS TRIBUNALES}

Se sostiene que la jurisprudencia constitucional ha de ser considerada como auténtica fuente del derecho, situada en un peculiar escalón, entre la misma Constitución y el legislador, cuya naturaleza parece ser, en cierto modo, superior a la propia ley, si bien la labor creadora de la jurisprudencia constitucional en nuestro sistema es ciertamente «parcial», limitada a aquel sector del ordenamiento que se le somete; mientras la construcción anglosajona es, en tal sentido, mucho más abierta, «originaria», por lo que la posición institucional del Tribunal puede resultar fundamental para que el resto de poderes asuma su doctrina en un caso de envergadura como el que da origen a la sentencia 31/2010.

Ahora bien, las condiciones en que se ha producido la gestación de la Sentencia no han sido todo lo pacíficas que debieran, de manera que parecía intuir-

${ }^{10}$ Con ello desaparece el presupuesto sociológico y cultural de su aceptación. Vid, supra nota 4 .

(C) UNED. Revista de Derecho Político 
se que esta resolución tendría un alto contenido interpretativo, como así ha sido $^{11}$. Una singularidad básica de la jurisprudencia constitucional es su valor frente a la jurisprudencia ordinaria y, en general, frente al resto de operadores jurídicos, lo que se concreta en un intenso deber de vinculación que afecta a todos los poderes públicos, vinculación que también se produce incluso en las sentencias que, declarando la constitucionalidad de la norma, realizan una interpretación conforme de los preceptos afectados ${ }^{12}$.

Todo ello tiene la consecuencia de que los efectos generales de la sentencia del Tribunal Constitucional habrían de ser trasladados a otros preceptos estatutarios sustancialmente idénticos pues, en palabras del Tribunal «los mencionados preceptos (en referencia a los arts. 164.1 CE y 40.2 y 87.1 LOTC) determinan por sí solos, una eficacia de las Sentencias de este Tribunal que no se proyecta únicamente respecto de los hechos pretéritos que fueron el objeto del proceso, sino que se extiende de algún modo hacia el futuro» (STC 230/2003, FJ 6), para lo que sólo parecen caber dos posibilidades: o el autor de la norma en cuestión procede a la derogación o bien, los diferentes operadores jurídicos legitimados pueden plantear una cuestión de inconstitucionalidad que deberá ser resuelta por el Tribunal de acuerdo con los fundamentos de la sentencia 31/2010, pero que pude tener una composición personal diferente. En todo caso, frente a la inalterabilidad de la ley, la jurisprudencia no es inalterable ${ }^{13}$, por lo que se puede entender que el Tribunal Constitucional puede modificar su jurisprudencia, si bien esa modificación debe sustentarse, a su vez, en la propia Constitución, parámetro de legitimidad del Tribunal ${ }^{14}$ y con ello habrá de contribuir, sin duda, a la legitimidad de todo el sistema institucional.

Ahora bien, este panorama se complica cuando la interpretación realizada, a pesar de mantenerse el tenor literal, vacía el contenido de la norma, lo reconstruye, le priva de eficacia jurídica o le hace decir lo que no dice, y además no se traslada al fallo la interpretación que afecta aun gran número de preceptos. Un

11 Para S. JULIA, «El arte de la interpretación», El País, 18 de julio de 2010, «lo complicado es que la sentencia, abrumadoramente interpretativa, reafirma la convicción de que todo es interpretable, y por tanto negociable, dependiente, pues, de la correlación de fuerzas. Y este sí que es el problema: que la puerta nunca del todo cerrada, se ha abierto de par en par para delicia de los especialistas en el arte de la interpretación y demás adictos a las tertulias».

12 Vid supra nota 5.

13 Ahora bien, la jurisprudencia del Tribunal Constitucional tiene reconocido un valor de fuente en el Art. 5.1 de la LOPJ. Sin embargo, los destinatarios de este precepto sólo son los Jueces y Tribunales, por lo que el propio Tribunal Constitucional queda fuera de esa vinculación, así como el legislador.

14 OSCAR G. CHASE. Opus cit.Pag. 126. 
nuevo tipo de de sentencia interpretativa es «programática» o sentencia «admonitoria», dirigida al legislador, al que invita a cubrir los espacios jurídicos que quedan vacíos por una declaración de inconstitucionalidad.

En este campo es importante determinar la diferente vinculación de las distintas partes de la sentencia: el fallo, los obiter dicta y la ratio decidendi. Si bien sólo el fallo y la ratio decidendi, en esencia esto último, conforman el material que pasa a ser vinculante, no se puede ignorar la fuerza jurídica de los obiter dicta, que en muchos casos son el origen de una nueva línea jurisprudencial o son la expresión de una suerte de diálogo de la más variada gama ${ }^{15}$, en el que dejan huella y traza las líneas de debate del propio Tribunal, de sus Magistrados, asî como las respuestas que se han ido dando a los puntos planteados desde una perspectiva doctrinal. Algo similar se puede decir respecto de los votos particulares.

\section{4. ÁMBITOS TEMÁTICOS AFECTADOS}

Es evidente que la Constitución es la norma fundamental de cada una de las Comunidades Autónomas, y que esa superioridad no se desplaza por los Estatutos de Autonomía que no pueden tener la consideración de una «ley orgánica omnicomprensiva» que regule todos los contenidos reservados constitucionalmente a las leyes orgánicas, cuya aprobación es competencia exclusiva del Estado ni pueden identificarse con la Constitución de un Estado miembro, la cual se aprueba sin intervención de las instancias centrales, aunque se encuentra sometida a la primacía de la Constitución federal. En definitiva, el Estatuto de Autonomía es una norma atributiva y delimitadora de las competencias de las Comunidades Autónomas, pero es la Constitución, y no los Estatutos, quien determina cuáles son las competencias estatales, que no pueden verse condicionadas ni afectadas por lo establecido en los Estatutos.

El Tribunal Constitucional, tras constatar (en la sentencia) que la Constitución no determina cuál es el contenido posible de un Estatuto de Autonomía, señala que hay un contenido necesario y mínimo, el del art. 147.2 y el impuesto por otros preceptos constitucionales (art. 69.5) y que, además, hay un contenido adicional, también previsto en la Constitución (arts. 3.2 y 4.2), recordando que según la STC 247/2007, existe otro contenido adicional que está en función de la cualidad de esta norma jurídica que, aunque no esté expresamente señalado en la

${ }^{15}$ G. DE VERGOTTINI. Opus cit. En este caso, esa adecuación se daría con la propia Constitución, o por mejor decir con el propio legislador, cuya voluntad expresada en la Ley (Estatuto) debe ser conservada. 
Constitución, «es complemento adecuado por su conexión con las aludidas previsiones constitucionales, adecuación que ha de entenderse referida a la función que en sentido estricto la Constitución encomienda a los Estatutos, en cuanto norma institucional básica que ha de llevar a cabo la regulación fundacional, institucional y competencial de cada Comunidad Autónoma» (STC 247/2007, FJ 12).

La sentencia analiza pues diferentes campos identitarios: Cataluña como nación (donde la STC estudia el valor jurídico de los preámbulos y la cuestión de los símbolos nacionales), los derechos históricos, la lengua propia (la condición del catalán como lengua propia y el deber del conocimiento del catalán). En materia de los derechos en los Estatutos de Autonomía (parte dogmática) la STC, aunque no se aparta radicalmente de las tesis de la STC 247/2007, es más proclive a su reconocimiento y supone un cambio de orientación jurisprudencial, si bien no determina qué derechos pueden ser acogidos en el Estatuto, lo que supone una renuncia al poder principialistas que cabe esperar de un tribunal Constitucional. En cuanto al régimen de garantía de estos derechos declara la inconstitucionalidad del Consejo de Garantías Estatutarias (órgano que ya había entrado en funcionamiento) constitucionales, decisión que no se comparte el libro, y del Sindic de Greuges, respecto del que se declara inconstitucional la expresión «con carácter exclusivo» de la función de proteger y defender los derechos y libertades reconocidos por la CE y por el EAC; prima en este punto el aspecto pragmático de la sentencia.

En cuanto al Poder Judicial, se pone de relieve que pese a la proclamación del principio de unidad judicial, difícilmente puede rechazarse alguna incidencia del principio autonómico sobre el Poder Judicial. Por lo que se refiere al Tribunal Superior de Justicia, es evidente que debe ser competente en todos los órdenes jurisdiccionales pues, en caso contrario, difícilmente culminarían las instancias procesales, pero el Estatuto no puede contraer la competencia del Tribunal Supremo. En cuanto al Consejo de Justicia se declara inconstitucional únicamente el art. 97, pero a juicio de los autores con una argumentación que deja mucho que desear., pues parte del error de creer que es un órgano autonómico.

En el estudio de las competencias: El reparto de competencias, competencias exclusivas, compartidas y de ejecución merece mención especial la técnica del blindaje competencial, sobre la cual no se pronuncia la sentencia, si bien sostiene que los títulos competenciales del Estado, incluidos los títulos horizontales, no pueden verse afectados por ninguna técnica de blindaje competencial, añadiendo que no es inconstitucional (el blindaje), siempre que se entienda que es meramente indicativo y descriptivo, y que la expresión «en todo caso» no excluya la confluencia de las competencias estatales. Se cierra este bloque con las relaciones institucionales (materia que merece reproche de inconstitucionalidad, si 
bien contiene algún apartado interpretativos) y la financiación (donde se declara inconstitucionales los arts. 106.3. (la capacidad legislativa autonómica para establecer los tributos de los gobiernos locales), 218 (el llamado esfuerzo fiscal similar) y se priva de naturaleza jurídica a la Disposición Adicional Tercera.

\section{LA INCIDENCIA DE LA SENTENCIA SOBRE OTRAS NORMAS}

La situación creada por la sentencia va a obligar a una depuración del ordenamiento a través de la vía del legislador, mediante la desaparición de los preceptos declarados inconstitucionales y que se repiten en gran medida en otras normas, pues en otro caso, únicamente seria la vía de la cuestión de inconstitucionalidad, con los problemas que ello conlleva, la válida para proceder a la depuración del ordenamiento jurídico. La sentencia proyecta sus efectos sobre una serie de campos tales como la reforma constitucional ${ }^{16}$, otros Estatutos y procesos de reforma estatutaria, legislación estatal y legislación autonómica catalana.

\section{CONCLUSIÓN}

La sentencia confirma la necesidad de una reflexión del propio Tribunal Constitucional, pero también de los agentes políticos relevantes, sobre lo que se puede exigir y se debe esperar del Tribunal Constitucional en el ámbito social y cultural de la sociedad española del siglo XXI. La clarificación de los papeles de cada institución, el ejercicio responsable de las funciones, y en especial, el respeto del reparto y división de poderes, son los puntos sobre los que se abre la necesidad de reflexión. Como ejemplo de todo ello se debe decir que, en efecto, la jurisprudencia no forma parte del bloque de constitucionalidad y que los Estatutos de Autonomía si; que los Tribunales Constitucionales actúan como legisladores negativos, incluso, excepcionalmente, como legisladores positivos, pero que resulta absolutamente rechazables que se conviertan en un poder constituyente infalible y permanente, que, desde el punto de vista de las exigencias que representa el principio de seguridad jurídica, el Tribunal Constitucional no parece haber estado a la altura de las circunstancias exigidas y que, terminan los autores, la STC 31/2010, por culpa de unos y de otros, debe ser considerada como una ocasión perdida de consolidación definitiva de nuestro modelo de Estado.

${ }^{16}$ Ese deberá haber sido el camino: reforma constitucional y tras ella la reforma de los estatutos.

(C) UNED. Revista de Derecho Político 


\section{Title}

On the legal consequences of the STC 31/2010 (28th June) about the statute of Catalonia

\section{Sumary}

1. Institutional normality. 2. Sociology, culture and Constitutional Court. 3. The Constitutional jurisprudence. Freedom of the Courts. 4. Subject areas affected. 5. The incidence of the judmet on the others standars. 6. Conclusions

\section{Resumen}

En este breve comentario se analizan las consecuencias jurídicas de la Sentencia 31/2010, de 28 de junio, del Tribunal Constitucional sobre el Estatuto de Cataluña, haciendo especial mención a las opiniones de los profesores Enrique Álvarez Conde y Rosario Tur Alsina.

\section{Abstract}

This brief review analuzes the legal consequences of the STC 31/2010 of 28 June, of the Spanish Constitutional Court on the Statute of Catalonia, with special reference to the views of profesors Enrique Álvarez Conde and Rosario Tur Alsina.

\section{Palabras clave:}

Cataluña, Tribunal Constitucional.

Key words

Catalonia, Constitutional Court. 